\title{
The Anti-asthmatic Effect of Intratracheally Treated Mesenchymal Stem Cells via Modulation of Lung Macrophage Activation
}

\section{Hanbit Kang}

Seoul National University College of Medicine

\section{Yosep Mo}

Seoul National University College of Medicine Jaewoo Shin

Seoul National University College of Medicine Hye Young Kim

Seoul National University College of Medicine

\section{Sang-Heon Cho}

Seoul National University College of Medicine

Hye-Ryun Kang ( $\nabla$ helenmed@snu.ac.kr)

Seoul National University College of Medicine

https://orcid.org/0000-0002-2317-4201

\section{Research}

Keywords: asthma, mesenchymal stem cells, macrophage activation, administration, inhalation

Posted Date: October 16th, 2020

DOl: https://doi.org/10.21203/rs.3.rs-91543/v1

License: (1) This work is licensed under a Creative Commons Attribution 4.0 International License. Read Full License 


\section{Abstract}

\section{Background}

Mesenchymal stem cells (MSCs) possess immunomodulatory properties that provide therapeutic potential for the treatment of inflammatory diseases. While the therapeutic and clinical effects of MSCs are partially known, the effects of its administration to the airway in asthma, a chronic airway inflammatory disease, remain unclear.

\section{Methods}

Six-week-old female BALB/c mice were sensitized and challenged with ovalbumin. The effects of intratracheally administered umbilical cord MSCs were evaluated by measuring airway hyperresponsiveness, airway inflammatory cell analysis, histological analysis, flow cytometry, and quantitative real-time PCR. Furthermore, ex vivo experiments confirmed the effect of MSC treatment on macrophages that originated from bronchoalveolar lavage fluid and were treated with interleukin (IL)-4 to induce M2 activation. Additionally, an in vitro transwell assay confirmed the effect of MSCs on macrophage activation through direct or indirect treatment using the CRL-2019 alveolar macrophage (AM) cell line.

Results

Intratracheal administration of MSCs significantly decreased the elevated levels of inflammatory cells and airway resistance in the murine asthma model. MSC administration also significantly decreased the numbers of Th2 cells, ILC2, and macrophages in the lungs of asthmatic mice. In particular, MHCll and CD86 expression was prominently reduced in dendritic cells and AMs following MSC treatment. Suppressed SiglecF ${ }^{+} \mathrm{CD} 11 \mathrm{c}^{+} \mathrm{CD} 11 \mathrm{~b}^{-}$resident $\mathrm{AMs}$, presenting strong negative correlation with type II inflammatory cells such as Th2 cells, ILC2, and eosinophils, were restored by intratracheal MSC treatment. Typical macrophage polarization to M2, particularly M2a, was significantly diminished. Expression levels of markers presenting M2 polarization and Th2 inflammation were decreased in the asthma model upon MSC administration. Ex vivo experiments of IL-4 treated AMs confirmed that MSC treatment reduced II-12 and Tnfa expression as well as that of M2 markers such as Cd206 and Retnla. In vitro experiments of IL-4 treated AMs confirmed that both direct and indirect MSC treatments through transwells significantly reduced II-5 and II- 13 expression. No difference between the two treatment methods was found.

\section{Conclusions}

Umbilical cord MSCs appear to regulate pulmonary macrophages, suppress Th2 inflammation, and mediate anti-asthmatic effects via soluble mediators.

\section{Background}


Asthma is a chronic inflammatory disease characterized by airway hyperresponsiveness (AHR), airway obstruction, and remodeling. Allergic asthma is characterized by type 2 T-helper (Th2) inflammation exhibiting elevated levels of IgE and eosinophil infiltration [1]. Severe asthma is refractory to high-dose inhaled corticosteroids, and requires new safe and effective anti-inflammatory treatment [2].

Mesenchymal stem cells (MSCs) are progenitor cells with multipotent, non-hematopoietic, self-renewing capabilities. Typically, they differentiate into bone marrow-derived MSCs (bmMSCs), umbilical cordderived MSCs (ucMSCs), or adipose tissue-derived MSCs (ASCs) [3]. It was recently discovered that MSCs affect various immune cells as well [4]. Additionally, although MSCs have been reported to affect macrophage polarization, the details of macrophage subtype changes in response to MSC treatment are not firmly established in asthma [5].

Macrophages, the most common immune cells in the airway, take charge of the innate immune response and can differentiate into $\mathrm{M} 1$ or $\mathrm{M} 2$ macrophages upon stimulation [6, 7]. Macrophage differentiation is influenced by stimuli as well as the microenvironment. More specifically, crosstalk with Th cells can largely drive macrophage differentiation. M1 macrophages are induced by Th1 stimulation, such as by interferon-y (IFN- $\mathrm{Y})$, and are characterized as pro-inflammatory macrophages [8]. In contrast, M2 macrophages are induced by Th2 stimulation, such as by interleukin (IL)-4 and IL-13, and are characterized as anti-inflammatory macrophages [9]. Although individual types of macrophages are known to play a variety of roles in different diseases, recent experiments with murine asthma models have confirmed the relationship between $\mathrm{M} 2$ macrophages and the pathophysiology of asthma. This has led to the proposal that regulating macrophage activation is a potential target for asthma treatment [10].

This study investigated the anti-asthmatic effects of intratracheally administered ucMSCs in an ovalbumin (OVA)-induced murine asthma model. Furthermore, the effect of ucMSCs on macrophage subtypes and innate immune cell activation was characterized.

\section{Materials And Methods}

\section{Murine asthma model}

Female 6-week-old BALB/c mice were purchased from Orient Bio (Anyang, Korea). The experiments were approved by the Institutional Animal Care and Use Committee of the Institute of Laboratory Animal Resources at Seoul National University (SNU-200302-2-2).

Mice were sensitized with $100 \mu \mathrm{g}$ OVA and $2 \mathrm{mg}$ aluminum hydroxide (Alum, Sigma-Aldrich; St. Louis, MO) by intraperitoneal injection on days 0 and 7 , and allergen challenge was performed by intraperitoneal injection of $50 \mu \mathrm{g}$ OVA on days $14,15,16,21,22$, and 23.

All human uc-MSCs used in this study were cultured, and prepared from Professor In-kyu Kim's laboratory (College of Medicine, Seoul National University, Seoul, Korea). A total of $1 \times 10^{5}$ ucMSCs were applied intratracheally on day 17 (Fig. S1). To identify changes in AHR and airway inflammation after ucMSC 
treatment, mice were divided into the following four groups $(n=4)$ : PBS (control group), ucMSC-treated (ucMSC group), OVA asthma (OVA group), and ucMSC-treated OVA asthma (OVA+ucMSC group).

\section{Measurement of airway hypersresponsivemenss and inflammation}

On day 24, AHR was measured using a Buxco ${ }^{\circledR}$ FinePointe system (FinePointe RC System, Buxco; Wilmington, NC). Mice were anesthetized with pentobarbital sodium $(50 \mathrm{mg} / \mathrm{kg})$, and lung resistance $\left(R_{L}\right)$ was measured for $3 \mathrm{~min}$. The measured $R_{L}$ values were subtracted from the baseline values and converted to a percentage.

On the same day, bronchoalveolar (BAL) fluid was obtained, and lung excision was performed. BAL cell slides were stained with Diff-Quik (Systmex; Kobe, Japan) and more than 300 cells were counted in each sample to determine the number of macrophages, neutrophils, eosinophils, and lymphocytes.

To confirm the pathological changes and characteristics of the lung parenchyma, the left lung of the mouse was fixed in $2 \%$ paraformaldehyde, embedded in paraffin, cut into 4 sections, and stained with hematoxylin and eosin.

\section{Cell analysis by flow cytometry}

Single-cell suspensions were treated with FcyR-blocking monoclonal antibody, and the cell surface and intracellular cytokines and transcription factors were stained accordingly (Figs. S2 and S3). Cells were analyzed with an LSR Fortessa X-20 (BD Biosciences; San Jose, CA) and FlowJo10 software (TreeStar; Woodburn, OR). After single-cell and lymphocyte gating, $T$ helper cells were defined as $C D 45^{+} C D 3^{+} C D 4^{+}$ cells. Regulatory T cells (Treg) were defined as those that expressed Foxp3, while cytokine-secreting effector Th cells were those that expressed IL-5, IL-13, IFN-y, and IL-17A (Fig. S2). After eosinophils were gated out, macrophages were defined as $\mathrm{CD} 45^{+} \mathrm{F} 4 / 80^{+}$cells, and dendritic cells (DCs) were defined as CD45 ${ }^{+} \mathrm{F} 4 / 80^{-} \mathrm{CD} 11 \mathrm{c}^{+}$cells.

M1 and M2 macrophages were defined as CD11c and CD206 single-positive cells, respectively, and M2 subtypes were subdivided into M2a (CD206 $\left.{ }^{+} \mathrm{MHCII}^{+} \mathrm{CD} 86^{-}\right)$, M2b (CD206 $\mathrm{MHCII}^{+} \mathrm{CD} 86^{+}$), and M2C (CD206 ${ }^{+}$MHCIICD86) [11-13]. In addition, by using CD11C and CD11b [14, 15], four clusters $\left(C D 11 c^{+} C D 11 b ;, C D 11 c^{+} C D 11 b^{+}, C D 11 c^{\text {int }} C D 11 b^{+}, C D 11 c^{-} C D 11 b^{+}\right)$were classified and analyzed (Fig. S3), and SiglecF ${ }^{+} \mathrm{CD} 11 \mathrm{c}^{+} \mathrm{CD} 11 \mathrm{~b}^{-}$were defined as resident $\mathrm{AMs}$ [16-18].

\section{Quantitative real-time PCR}

mRNA expression levels were measured with a 7500 real-time PCR system (Applied Biosystems; Foster City, CA) after converting the extracted RNA to cDNA using a SensiMix II probe kit (Bioline; London, UK). Expression levels in each sample were standardized against GAPDH expression using the $\Delta \Delta \mathrm{Ct}$ method, and the relative expression level for the control sample was calculated. The following primer sequences 
were used and verified by PrimerBank (Harvard, MA) (Table S1): Gapdh, Arg1, Retnla1, II-5, II-13, Cd86, II12, Tnfa, Cd206, and Tgfb1.

\section{Ex vivo and in vitro transwell experiments}

Macrophages from BAL fluid were cultured in 48-well plates $\left(1 \times 10^{4}\right.$ cells/well $)$ for $6 \mathrm{~h}$ and then stimulated with $20 \mathrm{ng} / \mathrm{L}$ of recombinant IL-4 (R\&D Systems; Minneapolis, MN) for $32 \mathrm{~h}$ (Fig. S4). Four groups were set up for ex vivo experiments: PBS (control group), ucMSC (ucMSC-treated group), IL-4 (IL-4stimulated group), and IL-4+ucMSC (IL-4-stimulated group treated with ucMSC). ucMSCs ( $1 \times 10^{4}$ cells $/ \mathrm{mL}$ ) were treated for $18 \mathrm{~h}$ after stimulation with recombinant IL-4 (Fig. S4A).

In vitro transwell experiments were conducted using Transwell Permeable Support (Costar; Kennebunk, ME). The CRL-2019 AM cell line was stimulated with IL-4 and treated with ucMSC as in the ex vivo experiment. Four groups were set up for the experiments: PBS (control group), IL-4 (IL-4-stimulated group), IL-4+DucMSC (IL-4-stimulated group directly pretreated with ucMSC), and IL-4+TucMSC (IL-4stimulated group indirectly treated with ucMSC via transwell system) (Fig. S4B).

\section{Statistical analysis}

All data are expressed as means \pm standard error of the mean (SEM). To analyze the correlation analysis between two groups, Spearman's rank-order correlation test was performed. Statistical analyses were performed using GraphPad Prism 7 software (GraphPad Software; San Diego, CA). The Mann-Whitney test was used to compare the two groups and p-values less than 0.05 were considered statistically significant.

\section{Results}

\section{Reduction of airway hyperresponsiveness and inflammation by ucMSC treatment in a murine asthma model}

To test the effect of ucMSCs on asthma, an OVA-induced asthma model was established, followed by intratracheal ucMSC treatment. ucMSC treatment significantly decreased AHR and airway inflammation enhanced by OVA challenge (Fig. 1A, B). The macrophage and eosinophil infiltration found in the OVA group around the bronchi and the blood vessels was strikingly reduced in the histological analysis of the OVA+ucMSC group (Fig. 1C). In addition, the increase in eosinophils in the lungs seen in the OVA group was significantly decreased in the OVA+uCMSC group, whereas the number of neutrophils did not change in the OVA+ucMSC group in flow cytometry analysis (Fig. S5).

\section{Reduction of Th2 and ILC2 by ucMSC treatment in a murine asthma model}

The number of total CD $4^{+} \mathrm{T}$ cells and IL-5/IL-13-secreting $\mathrm{CD} 4^{+} \mathrm{T}$ cells was significantly increased in the OVA group. Intratracheal ucMSC treatment significantly decreased the number of IL-5/IL-13-secreting 
$\mathrm{CD}^{+}{ }^{+} \mathrm{T}$ cells (Fig. 2A). On the other hand, no significant change was observed in IFN- $\gamma$ - or IL-17A-secreting CD $4^{+} \mathrm{T}$ cells or Treg cells following ucMSC treatment (Fig. 2A).

The total number of innate lymphoid cells (ILCs) and IL-5/IL-13-secreting type 2 ILCs (ILC2s) significantly increased in the OVA group, and ucMSC treatment significantly reduced total ILCs and ILC2s. Similar to Th1 and Th17 cells, IFN-y-secreting ILC1s and IL-17A-secreting ILC3s increased in the OVA-induced group but were not changed by intratracheal ucMSC treatment (Fig. 2B).

\section{Changes in dendritic cells and macrophages by ucMSC treatment in a murine asthma model}

OVA challenge increased the number of DCs in the lung, especially those with enhanced expression of $\mathrm{MHCll}$ and CD86. Although uCMSC treatment did not reduce the total number of DCs, mature DCs with antigen-presenting properties ( $\mathrm{MHCII}{ }^{+} \mathrm{CD} 86^{+} \mathrm{DCs}$ ) diminished significantly by ucMSC treatment. In contrast, immature DCs without MHCII and CD86 expression were reduced in the OVA group and were partially recovered by ucMSC treatment (Fig. $3 A$ ). Similarly, the increase in $M H C I I^{+} \mathrm{CD} 86^{+} \mathrm{AMs}$ in the OVA group was also reduced by treatment with ucMSC, whereas the diminished immature MHCIl-CD86-AMs in the OVA group were restored to normal levels by intratracheal treatment with ucMSCs (Fig. 3B).

OVA challenge increased both M1 and M2 macrophages, which were decreased by ucMSC treatment. Of the two subsets, M2 macrophages were more effectively reduced by ucMSCs, considering that the M2/M1 ratio significantly decreased in the OVA+ucMSC group (Fig. 3C).

Among M2 subtypes, ucMSC treatment significantly reduced M2a and M2c populations, which showed very strong positive correlations with type II immune cells such as IL-5- or IL-13-secreting CD $4^{+} \mathrm{T}$ cells, IL5- or IL-13-secreting ILC2s, and eosinophils (Fig 3E and S6). However, the M2b population, which also showed a significant increase in the OVA group, did not change upon ucMSC treatment (Fig. 3D).

As a result of analyzing $\mathrm{F} 4 / 80^{+}$macrophages based on $\mathrm{CD} 11 \mathrm{c}$ and $\mathrm{CD} 11 \mathrm{~b}$, it was possible to classify them into different clusters: CD11 $\mathrm{c}^{+} \mathrm{CD} 11 \mathrm{~b}^{-}, \mathrm{CD} 11 \mathrm{c}^{+} \mathrm{CD} 11 \mathrm{~b}^{+}, \mathrm{CD} 11 \mathrm{c}^{-} \mathrm{CD} 11 \mathrm{~b}^{+}$, and CD11c-CD11 $\mathrm{b}^{-}$(Fig. S7). SiglecF expression was very high in $\mathrm{CD} 11 \mathrm{C}^{+} \mathrm{CD} 11 \mathrm{~b}^{-}$macrophages (Fig. $4 \mathrm{~A}$ ), and this population was regarded as resident AMs. These resident AMs were significantly reduced in OVA-treated groups, and they were restored by ucMSC treatment (Fig. 4B). SiglecF ${ }^{+} \mathrm{CD} 11 \mathrm{C}^{+} \mathrm{CD} 11 \mathrm{~b}^{-}$macrophages showed strong negative correlations with type 2 immune cells (Fig. 4C).

\section{Changes in mRNA expression by ucMSC treatment in in vivo, ex vivo, and in vitro experiments}

Analysis of mRNA expression levels in mouse lung homogenates confirmed that ucMSC treatment downregulated the expression levels of both M1 and M2 markers upregulated by OVA challenge. Enhanced expression of M2 markers (Arg1 and Retn/a) and Th2 cytokines (II-13 and II-5) in the OVA group were significantly reduced by ucMSC treatment (Fig. 5A). Similarly, ucMSCs also downregulated CD86, II12, and Tnfa, classified as M1 markers, upregulated by OVA challenge (Fig. 5B). 
In order to directly specify the effect of ucMSCs on macrophages, BAL fluid macrophages were collected and stimulated with IL-4 ex vivo to induce M2 macrophage polarization in the presence and absence of ucMSC treatment. mRNA expression of M1 markers (II-12 and Tnfa), M2 markers (Cd206 and Arg 1), and Th2 cytokines (II-5, IL-13, and Tgfb1) were enhanced by IL-4 treatment and normalized by ucMSC treatment (Figs. 6A, 6B).

In addition, to determine whether ucMSCs directly or indirectly affect macrophages, the CRL-2019 AM cell line stimulated with IL-4 was treated with ucMSCs directly or indirectly via transwells, which suppressed Th2 cytokines in both groups (Fig. 6C).

\section{Discussion}

In this study, treating OVA-induced murine asthma models with ucMSCs resulted in anti-asthmatic effects by reducing type II airway inflammation and AHR. Particularly, ucMSC treatment decreased DCs and macrophages with antigen-presenting capacity. It also promoted the recovery of resident AMs, which contributed to the suppression of inflammation and maintenance of homeostasis in the lung.

Additionally, ucMSCs affected macrophages even without direct cell-to-cell contact, suggesting that soluble factors mediate the effect of ucMSCs.

Stem cells are undifferentiated cells that self-renew via cell division and multiply into differentiated cells specialized for tissues and organs depending on the environment. MSCs are adult stem cells derived from several sources, such as the placenta, umbilical cord, and adipose tissue, and they can differentiate into various lineages [19-22]. A recent study confirmed that transplanted MSCs retain their immunoregulatory properties even in allogenic treatment [23-26]. When mice were treated with human bmMSCs, the development and function of immune effector cells and T-cells were affected [27, 28]. When bmMSCs were intravenously injected in the murine asthma model, bmMSCs were localized in the lung, resulting in downregulated airway inflammation and Th2 cytokines [25]. Compared to MSCs originating from the bone marrow or other adult organs $[29,30]$, ucMSCs are favorable because they can be harvested non-invasively and mass-produced for in vitro experiments, and most importantly, with less ethical limitations [31, 32]. In comparison with bmMSCs, ucMSCs have reportedly demonstrated superior immunosuppressive effects and have thus been identified as a potential treatment for patients with asthma [29, 33-35]. Until now, human-derived bmMSC studies account for the majority of MSC studies [36]. Recent ucMSC studies demonstrating its anti-asthmatic effect mainly proved its inhibitory effect on Th2 and eosinophilic inflammation $[37,38]$.

Consistent with previous studies, we also successfully demonstrated the reduction of type II inflammation. In vivo experiments in this study confirmed that Th2 lymphocytes and ILC2s that produce IL-5 and IL-13 and induce type 2 inflammation in the lungs were decreased, confirming that ucMSCs affect not only adaptive immunity but also innate immunity. Studies have reported activation of Tregs as an inhibitory mechanism of the Th2 response to the effect of ucMSCs [35]. However, while this study demonstrated that Tregs, which were defined as Foxp $3^{+} \mathrm{CD} 4^{+} \mathrm{T}$ cells, do indeed increase in the OVA group, 
there was no significant change in Tregs following intratracheal ucMSC administration. Therefore, it appears that when ucMSCs were intratracheally administered, the anti-asthmatic effects were not mediated by Tregs. Therefore, this study aimed to confirm the effect on lung macrophages induced by intratracheally ucMSC treatment by analyzing the macrophages and their subsets responding to external stimuli in the airway and intratracheally administered ucMSCs.

Macrophage activation is a dynamic process in which early macrophages react to environmental signals, such as cytokine signaling, and develop into functional macrophages [39]. When exposed to foreign substances, changes in tissue microenvironments cause macrophage polarization. In this experiment, the numbers of $\mathrm{MHCII}^{+} \mathrm{CD} 86^{+} \mathrm{DCs}$ and $\mathrm{AMs}$ were far higher in the OVA model than in the control group, but treatment with ucMSCs suppressed these numbers. This suggests that MSCs are involved in the alleviation of asthma by regulating the antigen-presenting ability of DCs as well as AMs. In an OVAinduced murine asthma model treated with bmMSCs, the reduction in the antigen-presenting ability of DCs suggests that bmMSCs possess anti-asthmatic properties by regulating DC activation [40].

Recently, several studies have been conducted to functionally classify macrophages, and it is suspected that macrophage subtypes are related to endotypes of asthma [41-43]. In asthma patients, an increase in M2 macrophages is generally observed. In particular, M2a macrophages are known to secrete IL-5 and IL13, which induce the activation of Th2 cells and the infiltration of eosinophils into the lungs [44]. In accordance with the severity of asthma, M2a macrophages expressing CD206 and MHCII increase dramatically, suggesting that M2a macrophages are closely involved in the pathophysiology of asthma [45]. Additionally, M2c macrophages have been reported to be crucial in the development of pulmonary fibrosis [46, 47], and in vitro experiments have confirmed that ASCs can regulate M2c macrophage activation [48]. This study further confirmed that treating an OVA-induced asthma model with ucMSCs resulted in a change in M2 macrophage subtypes. More specifically, M2a and M2c macrophages were found to have a strong positive correlation with Th2 cells, ILC2s, and eosinophils. The reduction of M2a and M2c macrophages suggested that the anti-asthmatic effects of ucMSCs may be mediated by the regulation of these $\mathrm{M} 2$ macrophage subtypes.

AMs are principal immune cells that reside in the lungs and come in close contact with foreign substances through gaseous exchange. As the first line of defense against invading respiratory pathogens, AMs suppress inappropriate immune responses to antigens $[49,50]$. Previous studies confirmed the immunosuppressive properties of AMs by demonstrating that AM depletion leads to enhanced antigen-presenting abilities in DCs, which then results in increased formation of secondary antibodies when an antigen is inhaled [51, 52]. Additionally, AM-starved, OVA-sensitized mice demonstrated an increase in eosinophilic inflammation and Th2 response, verifying that AMs suppress the Th2 response in an OVA-induced murine asthma model [53].

In order to confirm the role of ucMSCs in airway inflammation through macrophage, this study analyzed the overall changes in macrophages due to ucMSC treatment through CD11b and CD11c gating $[14,15]$. $\mathrm{CD} 11 \mathrm{~b}$, the subunit that constitutes the integrin $\mathrm{aM} \beta 2$, was found to aid the adhesion and migration of 
macrophages, and thus helps regulate phagocytosis and cell activation [54-56]. CD11c, the subunit that constitutes the integrin aX $\beta 2$, allows macrophages to bind to lipopolysaccharide (LPS) or act as a complement to engulf opsonized bacteria $[57,58]$. SiglecF, a marker related to eosinophil apoptosis, is expressed in eosinophils and AMs, yet is not found in interstitial macrophages or inflammatory macrophages [16-18]. Although SiglecF is a marker of eosinophils, eosinophils are CD11c ${ }^{-}$cells and could be excluded from this study, which analyzed $\mathrm{CD} 11 \mathrm{c}^{+}$cells. Therefore, SiglecF ${ }^{+} \mathrm{CD} 11 \mathrm{c}^{+} \mathrm{CD} 11 \mathrm{~b}^{-}$ macrophages may represent typical resident AMs with homeostatic function in a steady state. Interestingly, ucMSCs increased SiglecF ${ }^{+} \mathrm{CD} 11 \mathrm{c}^{+} \mathrm{CD} 11 \mathrm{~b}^{-}$resident $\mathrm{AMs}$, and this population was strongly negatively correlated with Th2 cells, ILC2s, and eosinophils in this study. These results show that ucMSCs alleviate asthma by suppressing type 2 inflammation by recovering the depleted SiglecF ${ }^{+} \mathrm{CD} 11 \mathrm{c}^{+} \mathrm{CD} 11 \mathrm{~b}^{-}$ macrophage population. In accordance with this study, another study using OVA-induced asthma models reported that $\mathrm{CD} 11 \mathrm{c}^{+} \mathrm{CD} 11 \mathrm{~b}^{\text {low }} \mathrm{AMs}$ were significantly reduced upon OVA challenge but were also restored upon treatment with human MSCs, and in vivo depletion of AMs abrogated the therapeutic effects of human MSCs on allergic airway inflammation and AHR [29].

Recent studies confirming the immunosuppressive properties of allogenic MSCs have proposed that soluble factors may be the main cause of their immunomodulatory effect [59-64]. Immune function regulation by human MSCs in mice may be mainly due to these immunosuppressive water-soluble agents, rather than direct cell-to-cell contact. When MSC-treated media were intratracheally administered to LPS-stimulated mice, inflammatory cells in BAL fluid were decreased [59], and other studies suggested that MSCs mediate immunosuppressive functions by secreting water-soluble agents such as IL-6, IL-10, prostaglandin E2, and nitric oxide [60-64].

Through ex vivo experiments, we confirmed that the expression of $\mathrm{M} 1-, \mathrm{M} 2-$, and Th2-related markers decreased with ucMSC treatment. Through in vitro experiments, we found that administering ucMSCs directly or indirectly via transwell decreased the expression of both IL-5 and IL-13, with no significant difference between the two experimental groups. This further supports the idea that ucMSCs suppress type 2 inflammation by regulating macrophage activation via soluble mediators rather than direct cell-tocell contact.

This study confirmed the effect of intratracheally administered ucMSCs on lung macrophage differentiation in a murine asthma model, suggesting that direct delivery of ucMSCs to airways are a potential treatment for asthma. Further studies are needed to show the in vivo effects of MSC-induced SiglecF ${ }^{+} \mathrm{CD} 11 \mathrm{c}^{+} \mathrm{CD} 11 \mathrm{~b}^{-}$macrophages and to investigate the mechanisms by which ucMSCs regulate macrophage activation via soluble mediators.

In conclusion, intratracheally administered ucMSCs inhibit AHR and type II inflammation, which may be mediated by macrophage regulation in the asthmatic lung. In particular, ucMSC reduced the levels of M2a and M2c macrophages, suppressed the antigen-presenting capacity of DCs and AMs, and increased resident AMs. These regulatory properties of ucMSCs support the potential therapeutic implication of ucMSCs in allergic asthma. 


\section{Abbreviations}

AHR: airway hyperresponsiveness

AM: alveolar macrophage

BAL: bronchoalveolar lavage

DC: dendritic cell

FACS: fluorescence-activated cell sorting

ILC: innate lymphoid cell

OVA: ovalbumin

Th2: type $2 \mathrm{~T}$ helper

ucMSC: human umbilical cord-derived mesenchymal stem cell

\section{Declarations}

Acknowledgments: The authors would like to express their gratitude to Professor In-Gyu Kim of Seoul National University College of Medicine for providing ucMSC and Ms. Lucy Kim for her technical assistance for drafting manuscript.

Authors' contributions: HK made substantial contributions to the conception and design of the study, carried out the study, was involved in all animal experiments and all data collection, performed the statistical analysis, and drafted the manuscript. YM carried out the study, was involved in data collection and drafted the manuscript. HYK, SHC made substantial contributions to the conception and design of the study and co-supervised the study. HRK designed the study, interpreted the data, supervised the conduction of the study and drafting of the manuscript, and revised it critically. All authors read and approved the final manuscript.

Funding: This research was supported by the Bio \& Medical Technology Development Program of the National Research Foundation (NRF) funded by the Korean government (MSIT) (No. NRF2017M3A9B4061887).

Availability of data and materials: The data that support the findings of this study are available from the corresponding author upon reasonable request.

Ethics approval and consent to participate: All animal experimental procedures were conducted according to a protocol approved by the Institutional Animal Care and Use Committee of the Institute of Laboratory Animal Resources at Seoul National University 
Consent for publication: Not applicable

Competing interests: The authors have no conflicts of interest to declare.

\section{References}

1. Bosnjak B, Stelzmueller B, Erb KJ, Epstein MM. Treatment of allergic asthma: modulation of Th2 cells and their responses. Respir Res. 2011;12:114. doi: 10.1186/1465-9921-12-114.

2. Coverstone AM, Seibold MA, Peters MC. Diagnosis and Management of T2-High Asthma. J Allergy Clin Immunol Pract. 2020;8:442-50. doi: 10.1016/j.jaip.2019.11.020.

3. Han Y, Li X, Zhang Y, Han Y, Chang F, Ding J. Mesenchymal Stem Cells for Regenerative Medicine. Cells. 2019;8. doi: 10.3390/cells8080886.

4. Wang $Y$, Chen $X$, Cao W, Shi Y. Plasticity of mesenchymal stem cells in immunomodulation: pathological and therapeutic implications. Nat Immunol. 2014;15:1009-16. doi: 10.1038/ni.3002.

5. Abumaree MH, Al Jumah MA, Kalionis B, Jawdat D, Al Khaldi A, Abomaray FM, et al. Human placental mesenchymal stem cells (pMSCs) play a role as immune suppressive cells by shifting macrophage differentiation from inflammatory M1 to anti-inflammatory M2 macrophages. Stem Cell Rev Rep. 2013;9:620-41. doi: 10.1007/s12015-013-9455-2.

6. Muraille $\mathrm{E}$, Leo $\mathrm{O}$, Moser $\mathrm{M}$. TH1/TH2 paradigm extended: macrophage polarization as an unappreciated pathogen-driven escape mechanism? Front Immunol. 2014;5:603. doi: 10.3389/fimmu.2014.00603.

7. Saradna A, Do DC, Kumar S, Fu QL, Gao P. Macrophage polarization and allergic asthma. Transl Res. 2018;191:1-14. doi: 10.1016/j.trsl.2017.09.002.

8. Bosco MC. Macrophage polarization: Reaching across the aisle? J Allergy Clin Immunol. 2019;143:1348-50. doi: 10.1016/j.jaci.2018.12.995.

9. Moreira AP, Cavassani KA, Hullinger R, Rosada RS, Fong DJ, Murray L, et al. Serum amyloid P attenuates M2 macrophage activation and protects against fungal spore-induced allergic airway disease. J Allergy Clin Immunol. 2010;126:712-21 e7. doi: 10.1016/j.jaci.2010.06.010.

10. Fricker M, Gibson PG. Macrophage dysfunction in the pathogenesis and treatment of asthma. Eur Respir J. 2017;50. doi: 10.1183/13993003.00196-2017.

11. Mantovani A, Sica A, Sozzani S, Allavena P, Vecchi A, Locati M. The chemokine system in diverse forms of macrophage activation and polarization. Trends Immunol. 2004;25:677-86. doi: 10.1016/j.it.2004.09.015.

12. Klopfleisch R. Macrophage reaction against biomaterials in the mouse model - Phenotypes, functions and markers. Acta Biomater. 2016;43:3-13. doi: 10.1016/j.actbio.2016.07.003.

13. Liegeois M, Legrand C, Desmet CJ, Marichal T, Bureau F. The interstitial macrophage: A longneglected piece in the puzzle of lung immunity. Cell Immunol. 2018;330:91-6. doi:

10.1016/j.cellimm.2018.02.001. 
14. Duan M, Steinfort DP, Smallwood D, Hew M, Chen W, Ernst M, et al. CD11b immunophenotyping identifies inflammatory profiles in the mouse and human lungs. Mucosal Immunol. 2016;9:550-63. doi: 10.1038/mi.2015.84.

15. Janssen WJ, Barthel L, Muldrow A, Oberley-Deegan RE, Kearns MT, Jakubzick C, et al. Fas determines differential fates of resident and recruited macrophages during resolution of acute lung injury. Am J Respir Crit Care Med. 2011;184:547-60. doi: 10.1164/rccm.201011-18910C.

16. Poczobutt JM, De S, Yadav VK, Nguyen TT, Li H, Sippel TR, et al. Expression Profiling of Macrophages Reveals Multiple Populations with Distinct Biological Roles in an Immunocompetent Orthotopic Model of Lung Cancer. J Immunol. 2016;196:2847-59. doi: 10.4049/jimmunol.1502364.

17. Bochner BS. Siglec-8 on human eosinophils and mast cells, and Siglec-F on murine eosinophils, are functionally related inhibitory receptors. Clin Exp Allergy. 2009;39:317-24. doi: 10.1111/j.13652222.2008.03173.x.

18. Gautier EL, Shay T, Miller J, Greter M, Jakubzick C, Ivanov S, et al. Gene-expression profiles and transcriptional regulatory pathways that underlie the identity and diversity of mouse tissue macrophages. Nat Immunol. 2012;13:1118-28. doi: 10.1038/ni.2419.

19. Lee OK, Kuo TK, Chen WM, Lee KD, Hsieh SL, Chen TH. Isolation of multipotent mesenchymal stem cells from umbilical cord blood. Blood. 2004;103:1669-75. doi: 10.1182/blood-2003-05-1670.

20. Deng J, Petersen BE, Steindler DA, Jorgensen ML, Laywell ED. Mesenchymal stem cells spontaneously express neural proteins in culture and are neurogenic after transplantation. Stem Cells. 2006;24:1054-64. doi: 10.1634/stemcells.2005-0370.

21. Sato Y, Araki H, Kato J, Nakamura K, Kawano Y, Kobune M, et al. Human mesenchymal stem cells xenografted directly to rat liver are differentiated into human hepatocytes without fusion. Blood. 2005;106:756-63. doi: 10.1182/blood-2005-02-0572.

22. Pittenger MF, Mackay AM, Beck SC, Jaiswal RK, Douglas R, Mosca JD, et al. Multilineage potential of adult human mesenchymal stem cells. Science. 1999;284:143-7. doi:

10.1126/science.284.5411.143.

23. Jones BJ, McTaggart SJ. Immunosuppression by mesenchymal stromal cells: from culture to clinic. Exp Hematol. 2008;36:733-41. doi: 10.1016/j.exphem.2008.03.006.

24. Lee SM, Lee SC, Kim SJ. Contribution of human adipose tissue-derived stem cells and the secretome to the skin allograft survival in mice. J Surg Res. 2014;188:280-9. doi: 10.1016/j.jss.2013.10.063.

25. Bonfield TL, Koloze M, Lennon DP, Zuchowski B, Yang SE, Caplan Al. Human mesenchymal stem cells suppress chronic airway inflammation in the murine ovalbumin asthma model. Am J Physiol Lung Cell Mol Physiol. 2010;299:L760-70. doi: 10.1152/ajplung.00182.2009.

26. Abdallah BM, Kassem M. Human mesenchymal stem cells: from basic biology to clinical applications. Gene Ther. 2008;15:109-16. doi: 10.1038/sj.gt.3303067.

27. Caplan Al, Bruder SP. Mesenchymal stem cells: building blocks for molecular medicine in the 21st century. Trends Mol Med. 2001;7:259-64. doi: 10.1016/s1471-4914(01)02016-0. 
28. Crisan M, Deasy B, Gavina M, Zheng B, Huard J, Lazzari L, et al. Purification and long-term culture of multipotent progenitor cells affiliated with the walls of human blood vessels: myoendothelial cells and pericytes. Methods Cell Biol. 2008;86:295-309. doi: 10.1016/S0091-679X(08)00013-7.

29. Mathias LJ, Khong SM, Spyroglou L, Payne NL, Siatskas C, Thorburn AN, et al. Alveolar macrophages are critical for the inhibition of allergic asthma by mesenchymal stromal cells. J Immunol. 2013;191:5914-24. doi: 10.4049/jimmunol.1300667.

30. Castro LL, Kitoko JZ, Xisto DG, Olsen PC, Guedes HLM, Morales MM, et al. Multiple doses of adipose tissue-derived mesenchymal stromal cells induce immunosuppression in experimental asthma. Stem Cells Transl Med. 2020;9:250-60. doi: 10.1002/sctm.19-0120.

31. Majore I, Moretti P, Stahl F, Hass R, Kasper C. Growth and differentiation properties of mesenchymal stromal cell populations derived from whole human umbilical cord. Stem Cell Rev Rep. 2011;7:17-31. doi: 10.1007/s12015-010-9165-y.

32. Li T, Xia M, Gao Y, Chen Y, Xu Y. Human umbilical cord mesenchymal stem cells: an overview of their potential in cell-based therapy. Expert Opin Biol Ther. 2015;15:1293-306. doi:

10.1517/14712598.2015.1051528.

33. Li J, Xu SQ, Zhao YM, Yu S, Ge LH, Xu BH. Comparison of the biological characteristics of human mesenchymal stem cells derived from exfoliated deciduous teeth, bone marrow, gingival tissue, and umbilical cord. Mol Med Rep. 2018;18:4969-77. doi: 10.3892/mmr.2018.9501.

34. Chan CK, Wu KH, Lee YS, Hwang SM, Lee MS, Liao SK, et al. The comparison of interleukin 6associated immunosuppressive effects of human ESCs, fetal-type MSCs, and adult-type MSCs. Transplantation. 2012;94:132-8. doi: 10.1097/TP.0b013e31825940a4.

35. Huang YC, Parolini O, La Rocca G, Deng L. Umbilical cord versus bone marrow-derived mesenchymal stromal cells. Stem Cells Dev. 2012;21:2900-3. doi: 10.1089/scd.2012.0216.

36. Galderisi U, Giordano A. The gap between the physiological and therapeutic roles of mesenchymal stem cells. Med Res Rev. 2014;34:1100-26. doi: 10.1002/med.21322.

37. Chan CK, Lin TC, Huang YA, Chen YS, Wu CL, Lo HY, et al. The modulation of Th2 immune pathway in the immunosuppressive effect of human umbilical cord mesenchymal stem cells in a murine asthmatic model. Inflamm Res. 2016;65:795-801. doi: 10.1007/s00011-016-0961-y.

38. Kang SY, Park DE, Song WJ, Bae BR, Lee JW, Sohn KH, et al. Immunologic regulatory effects of human umbilical cord blood-derived mesenchymal stem cells in a murine ovalbumin asthma model. Clin Exp Allergy. 2017;47:937-45. doi: 10.1111/cea.12920.

39. Murray PJ. Macrophage Polarization. Annu Rev Physiol. 2017;79:541-66. doi: 10.1146/annurevphysiol-022516-034339.

40. Zeng SL, Wang LH, Li P, Wang W, Yang J. Mesenchymal stem cells abrogate experimental asthma by altering dendritic cell function. Mol Med Rep. 2015;12:2511-20. doi: 10.3892/mmr.2015.3706.

41. Chakarov S, Lim HY, Tan L, Lim SY, See P, Lum J, et al. Two distinct interstitial macrophage populations coexist across tissues in specific subtissular niches. Science. 2019;363. doi: 10.1126/science.aau0964. 
42. Gibbings SL, Thomas SM, Atif SM, McCubbrey AL, Desch AN, Danhorn T, et al. Three Unique Interstitial Macrophages in the Murine Lung at Steady State. Am J Respir Cell Mol Biol. 2017;57:6676. doi: 10.1165/rcmb.2016-03610C.

43. Ural BB, Yeung ST, Damani-Yokota P, Devlin JC, de Vries M, Vera-Licona P, et al. Identification of a nerve-associated, lung-resident interstitial macrophage subset with distinct localization and immunoregulatory properties. Sci Immunol. 2020;5. doi: 10.1126/sciimmunol.aax8756.

44. Byers DE, Holtzman MJ. Alternatively activated macrophages and airway disease. Chest. 2011;140:768-74. doi: 10.1378/chest.10-2132.

45. Girodet PO, Nguyen D, Mancini JD, Hundal M, Zhou X, Israel E, et al. Alternative Macrophage Activation Is Increased in Asthma. Am J Respir Cell Mol Biol. 2016;55:467-75. doi:

10.1165/rcmb.2015-02950C.

46. Lu J, Cao Q, Zheng D, Sun Y, Wang C, Yu X, et al. Discrete functions of M2a and M2c macrophage subsets determine their relative efficacy in treating chronic kidney disease. Kidney Int. 2013;84:74555. doi: 10.1038/ki.2013.135.

47. Mann CJ, Perdiguero E, Kharraz Y, Aguilar S, Pessina P, Serrano AL, et al. Aberrant repair and fibrosis development in skeletal muscle. Skelet Muscle. 2011;1:21. doi: 10.1186/2044-5040-1-21.

48. Sun M, Sun L, Huang C, Chen BC, Zhou Z. Induction of Macrophage M2b/c Polarization by Adipose Tissue-Derived Mesenchymal Stem Cells. J Immunol Res. 2019;2019:7059680. doi: $10.1155 / 2019 / 7059680$.

49. Peters-Golden M. The alveolar macrophage: the forgotten cell in asthma. Am J Respir Cell Mol Biol. 2004;31:3-7. doi: 10.1165/rcmb.f279.

50. Thepen T, Van Rooijen N, Kraal G. Alveolar macrophage elimination in vivo is associated with an increase in pulmonary immune response in mice. J Exp Med. 1989;170:499-509. doi: 10.1084/jem.170.2.499.

51. Holt PG, Oliver J, Bilyk N, McMenamin C, McMenamin PG, Kraal G, et al. Downregulation of the antigen presenting cell function(s) of pulmonary dendritic cells in vivo by resident alveolar macrophages. J Exp Med. 1993;177:397-407. doi: 10.1084/jem.177.2.397.

52. Thepen T, McMenamin C, Oliver J, Kraal G, Holt PG. Regulation of immune response to inhaled antigen by alveolar macrophages: differential effects of in vivo alveolar macrophage elimination on the induction of tolerance vs. immunity. Eur J Immunol. 1991;21:2845-50. doi:

10.1002/eji.1830211128.

53. Tang C, Inman MD, van Rooijen N, Yang P, Shen H, Matsumoto K, et al. Th type 1-stimulating activity of lung macrophages inhibits Th2-mediated allergic airway inflammation by an IFN-gammadependent mechanism. J Immunol. 2001;166:1471-81. doi: 10.4049/jimmunol.166.3.1471.

54. Solovjov DA, Pluskota E, Plow EF. Distinct roles for the alpha and beta subunits in the functions of integrin alphaMbeta2. J Biol Chem. 2005;280:1336-45. doi: 10.1074/jbc.M406968200.

55. Prudovsky I, Popov K, Akimov S, Serov S, Zelenin A, Meinhardt G, et al. Antisense CD11b integrin inhibits the development of a differentiated monocyte/macrophage phenotype in human leukemia 
cells. Eur J Cell Biol. 2002;81:36-42. doi: 10.1078/0171-9335-00219.

56. Simonin-Le Jeune K, Le Jeune A, Jouneau S, Belleguic C, Roux PF, Jaguin M, et al. Impaired functions of macrophage from cystic fibrosis patients: CD11b, TLR-5 decrease and SCD14, inflammatory cytokines increase. PLoS One. 2013;8:e75667. doi: 10.1371/journal.pone.0075667.

57. Ingalls RR, Golenbock DT. CD11 c/CD18, a transmembrane signaling receptor for lipopolysaccharide. J Exp Med. 1995;181:1473-9. doi: 10.1084/jem.181.4.1473.

58. Ihanus E, Uotila LM, Toivanen A, Varis M, Gahmberg CG. Red-cell ICAM-4 is a ligand for the monocyte/macrophage integrin CD11c/CD18: characterization of the binding sites on ICAM-4. Blood. 2007;109:802-10. doi: 10.1182/blood-2006-04-014878.

59. Goodwin M, Sueblinvong V, Eisenhauer P, Ziats NP, LeClair L, Poynter ME, et al. Bone marrow-derived mesenchymal stromal cells inhibit Th2-mediated allergic airways inflammation in mice. Stem Cells. 2011;29:1137-48. doi: 10.1002/stem.656.

60. Helal MAM, Shaheen NEM, Abu Zahra FA. Immunomodulatory capacity of the local mesenchymal stem cells transplantation after severe skeletal muscle injury in female rats. Immunopharmacol Immunotoxicol. 2016;38:414-22. doi: 10.1080/08923973.2016.1222617.

61. Bernardo ME, Fibbe WE. Mesenchymal stromal cells: sensors and switchers of inflammation. Cell Stem Cell. 2013;13:392-402. doi: 10.1016/j.stem.2013.09.006.

62. Sato K, Ozaki K, Oh I, Meguro A, Hatanaka K, Nagai T, et al. Nitric oxide plays a critical role in suppression of T-cell proliferation by mesenchymal stem cells. Blood. 2007;109:228-34. doi: 10.1182/blood-2006-02-002246.

63. Chen K, Wang D, Du WT, Han ZB, Ren H, Chi Y, et al. Human umbilical cord mesenchymal stem cells hUC-MSCs exert immunosuppressive activities through a PGE2-dependent mechanism. Clin Immunol. 2010;135:448-58. doi: 10.1016/j.clim.2010.01.015.

64. Shi Y, Su J, Roberts Al, Shou P, Rabson AB, Ren G. How mesenchymal stem cells interact with tissue immune responses. Trends Immunol. 2012;33:136-43. doi: 10.1016/j.it.2011.11.004.

\section{Figures}


Fig 1.

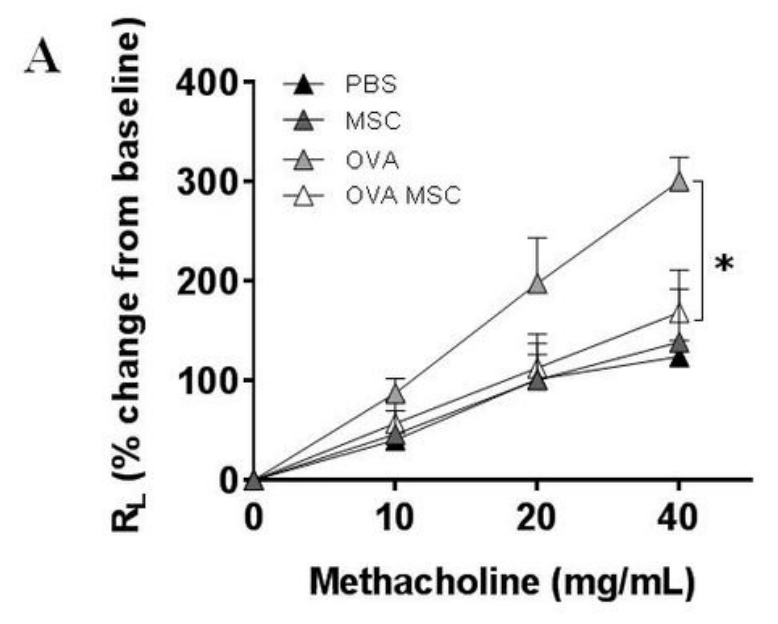

C

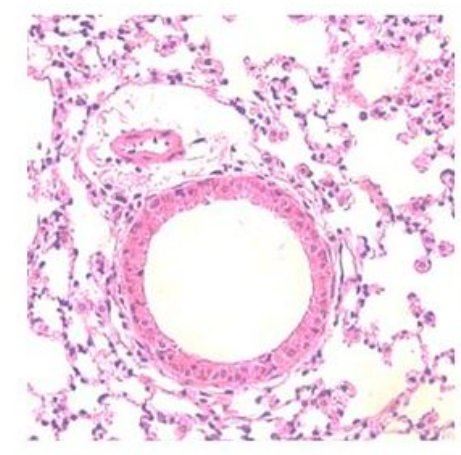

MSC
B
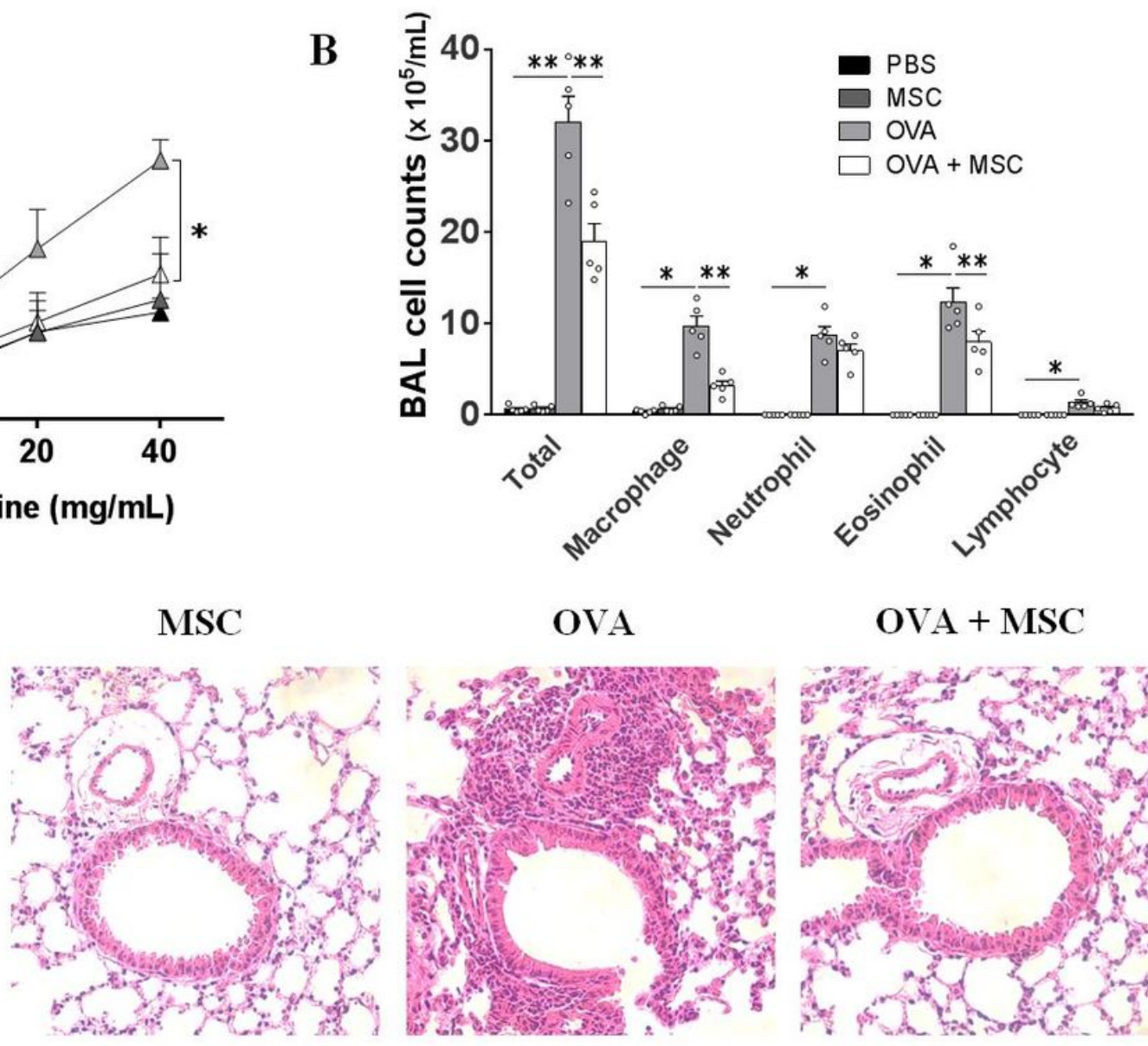

OVA

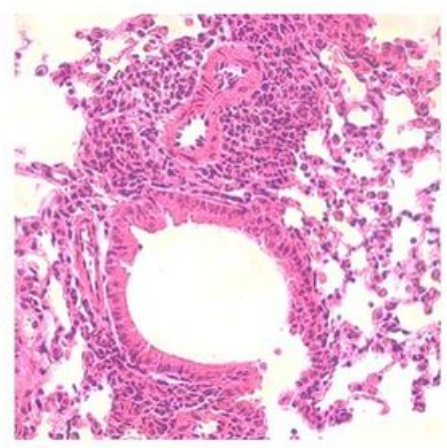

OVA + MSC



\section{Figure 1}

Effect of ucMSC on AHR and Lung Inflammation in a murine asthma model. (A) Methacholine hyperresponsiveness was measured $24 \mathrm{~h}$ after the last intranasal challenge. (B) The number of total inflammatory cells, including macrophages, neutrophils, eosinophils, and lymphocytes in BAL fluid. (C) H\&E stain $(\times 100)$ of lung histology after allergen challenge (i: PBS, ii: ucMSC, iii: OVA, iv: OVA + ucMSC group). $n=4-5$ for each group, * indicates $p<0.05$, ** indicates $p<0.01$. All results are representative of at least three independent experiments. BAL: bronchoavleolar lavage 
Fig 2.
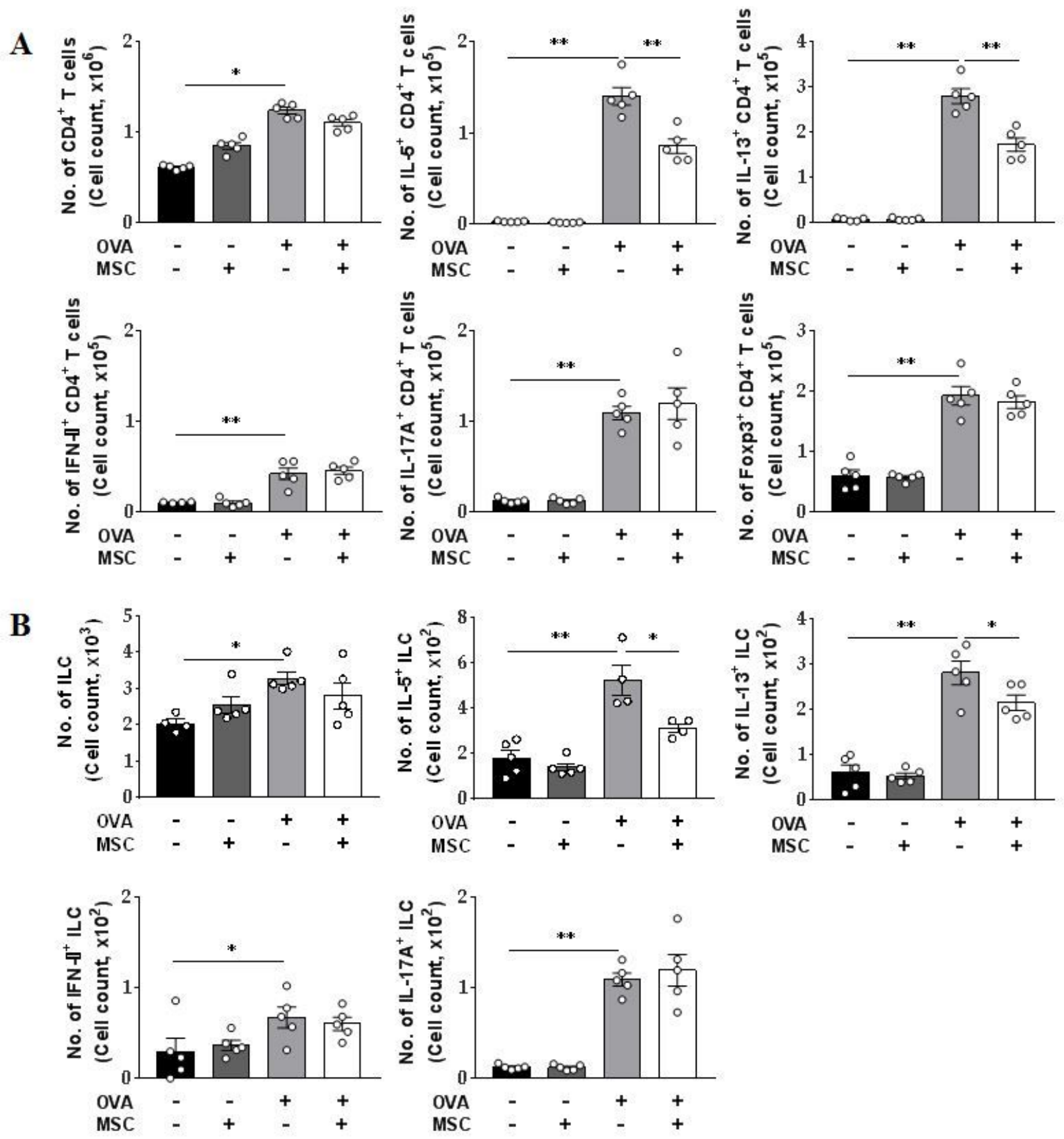

Figure 2

Effect of ucMSCs on Th2 and ILC2 by ucMSC treatment in a murine asthma model (A) The number of lung CD4+ $T$ cells, IL-5+CD4+ T cells, IL-13+CD4+ T cells, IFN- $\gamma+C D 4+T$ cells, IL-17A+CD4+ $T$ cells and Foxp3+CD4+ T cells. (B) The number of lung ILC, IL-5+ ILC, IL-13+ ILC, IFN- -+ ILC, and IL-17A+ ILC. $n=4-5$ for each group, * indicates $p<0.05$, ** indicates $p<0.01$. All results are representative of at least three independent experiments. 
Fig 3.

A

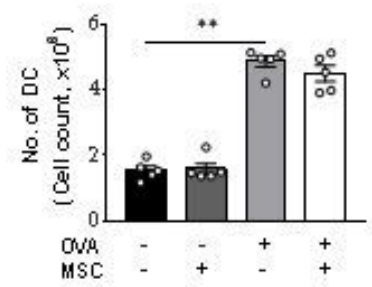

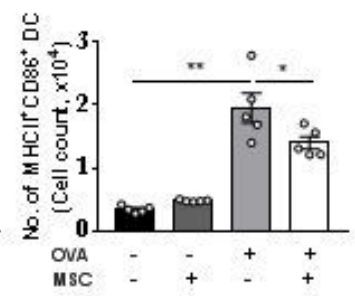

B
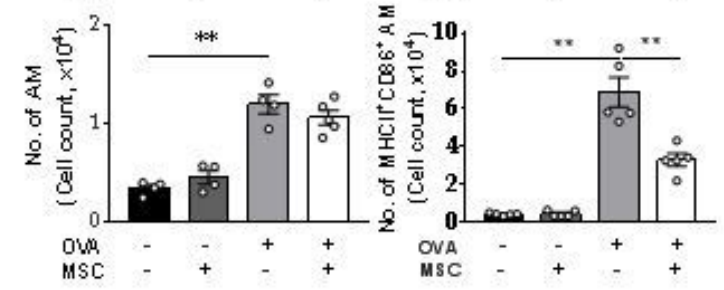

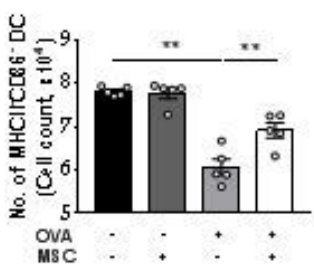

C
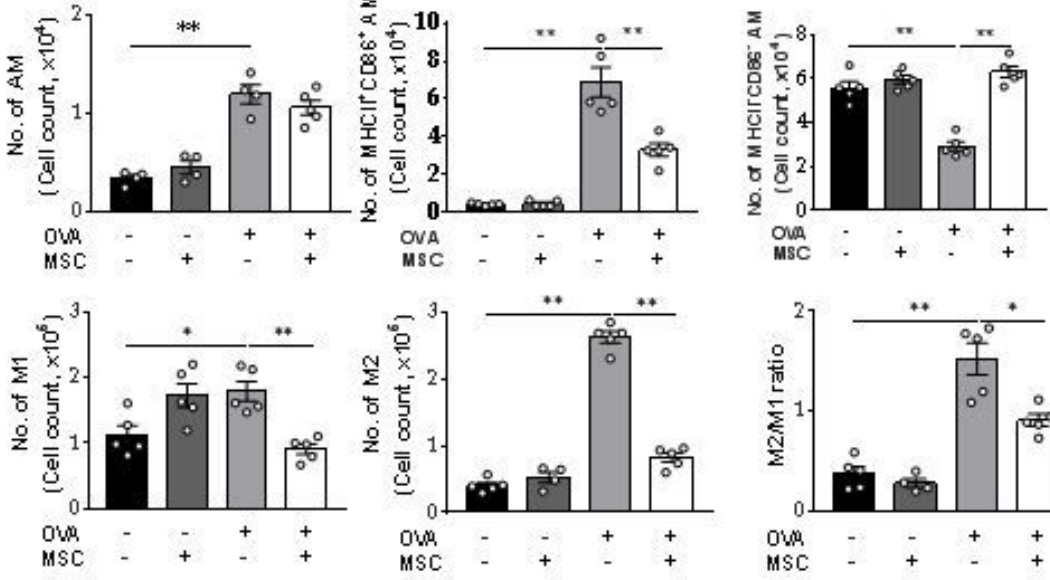

D
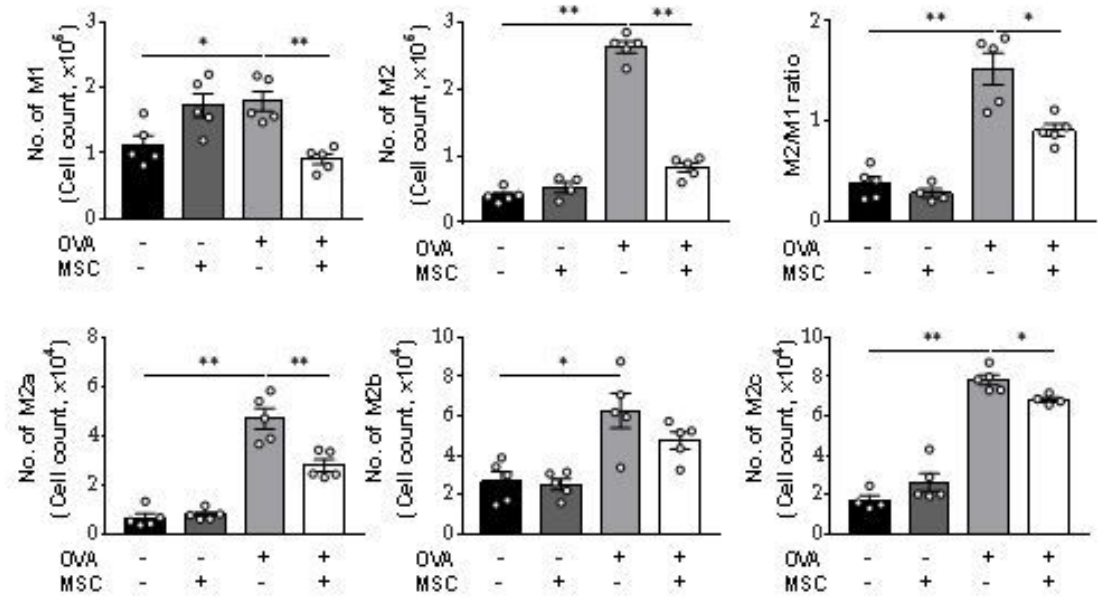

$\mathbf{E}$
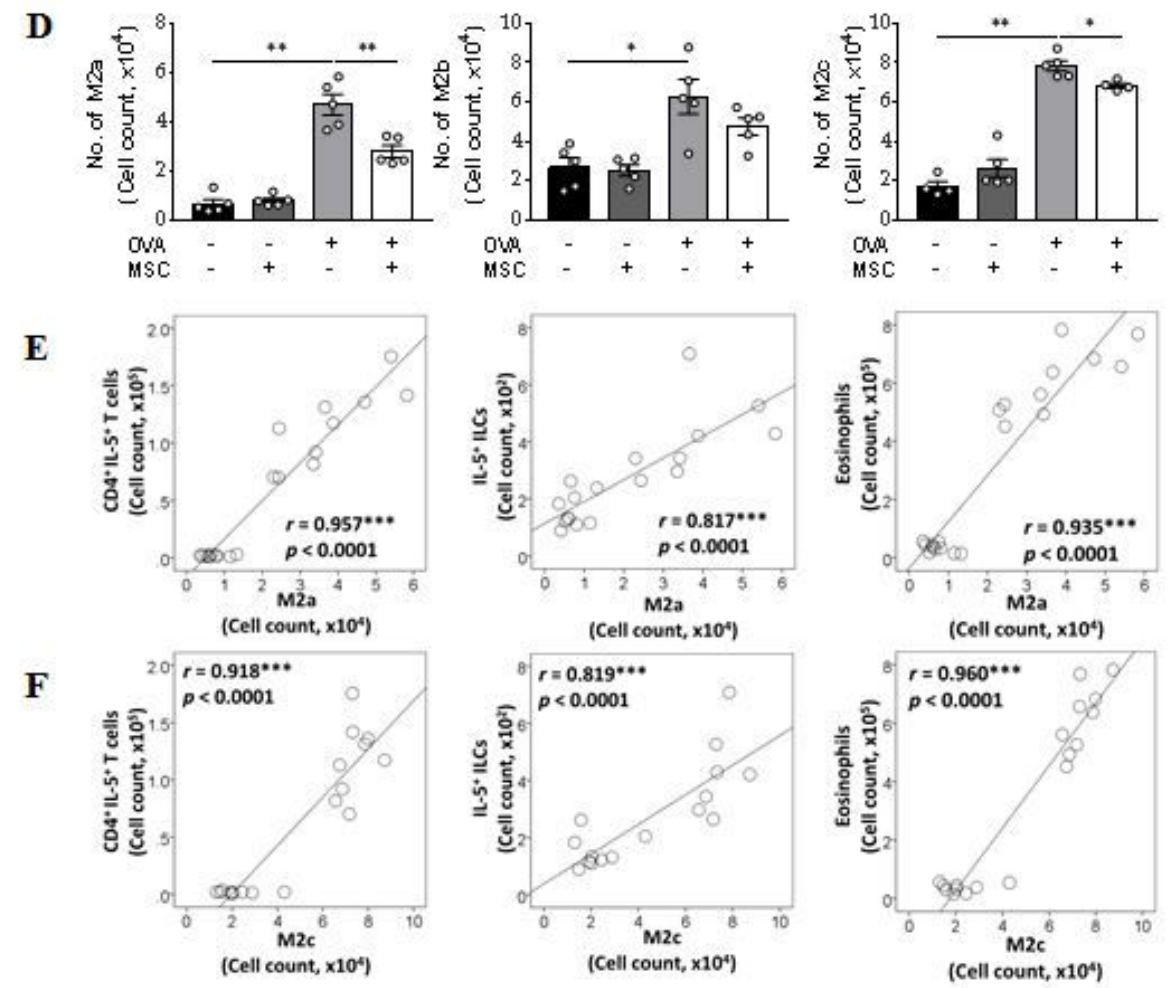

\section{Figure 3}

Effect of ucMSCs on DC and macrophages by ucMSC treatment in a murine asthma model $(A, B)$ The number of lung DC, MHCII+CD86+ DC, MHCII-CD86- DC (A), AM, MHCII+CD86+ AM, MHCII-CD86- AM (B).

(C) The number of lung M1, M2, and DN and the ratio of M2/M1. (D) The number of M2a, M2b, and M2c.

(E) Correlation plots between M2a macrophages and CD4+IL-5 T cells, IL-5+ILCs, and eosinophils. (F) Correlation plots between M2c macrophages and CD4+IL-5 T cells, IL-5+ILCs, and eosinophils. $n=4-5$ for 
each group, * indicates $p<0.05, * *$ indicates $p<0.01$, *** indicates $p<0.0001$. All results are representative of at least three independent experiments.

\section{Fig 4.}

A

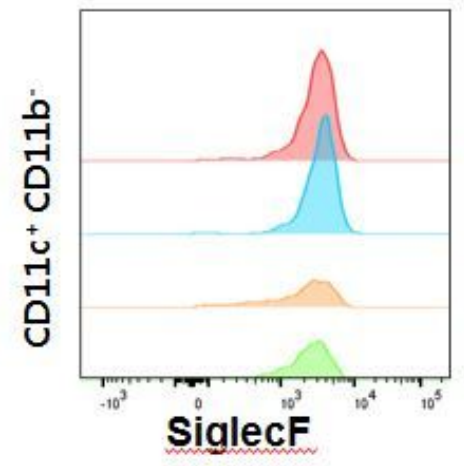

C
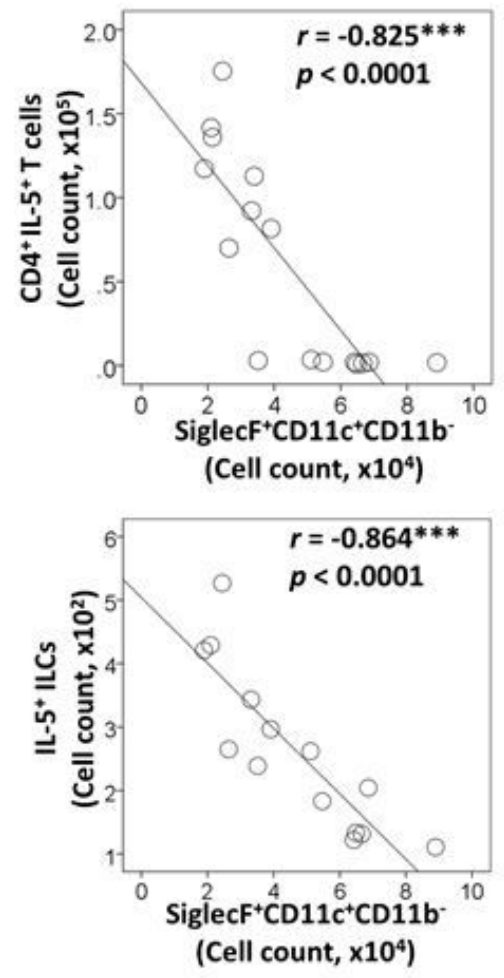

B

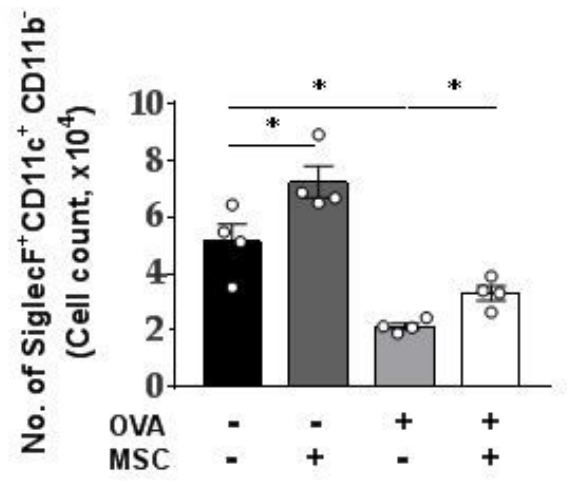

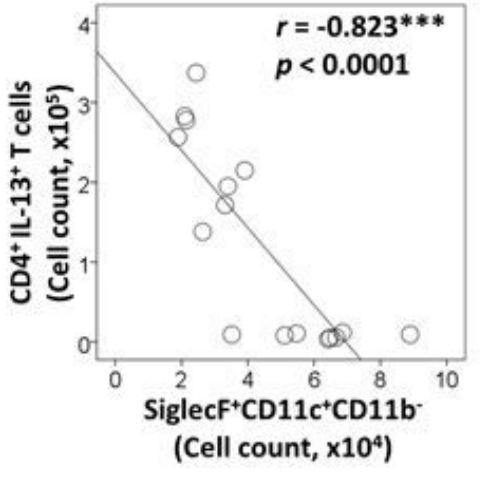



Figure 4

Effect of ucMSCs on CD11c+CD11b- macrophages in a murine asthma model. (A) Expression level of SiglecF on CD11c+CD11b- macrophages. (B) The number of CD11c+CD11b- macrophages. (B) Correlation plots between CD11C+CD11b- macrophages and CD4+IL-5+ T cells, CD4+IL-5+ T cells, eosinophils, IL-5+ ILCs, and IL-13+ ILCs. $n=4$, * indicates $p<0.05$, *** indicates $p<0.0001$. All results are representative of at least three independent experiments. 
Fig 5.
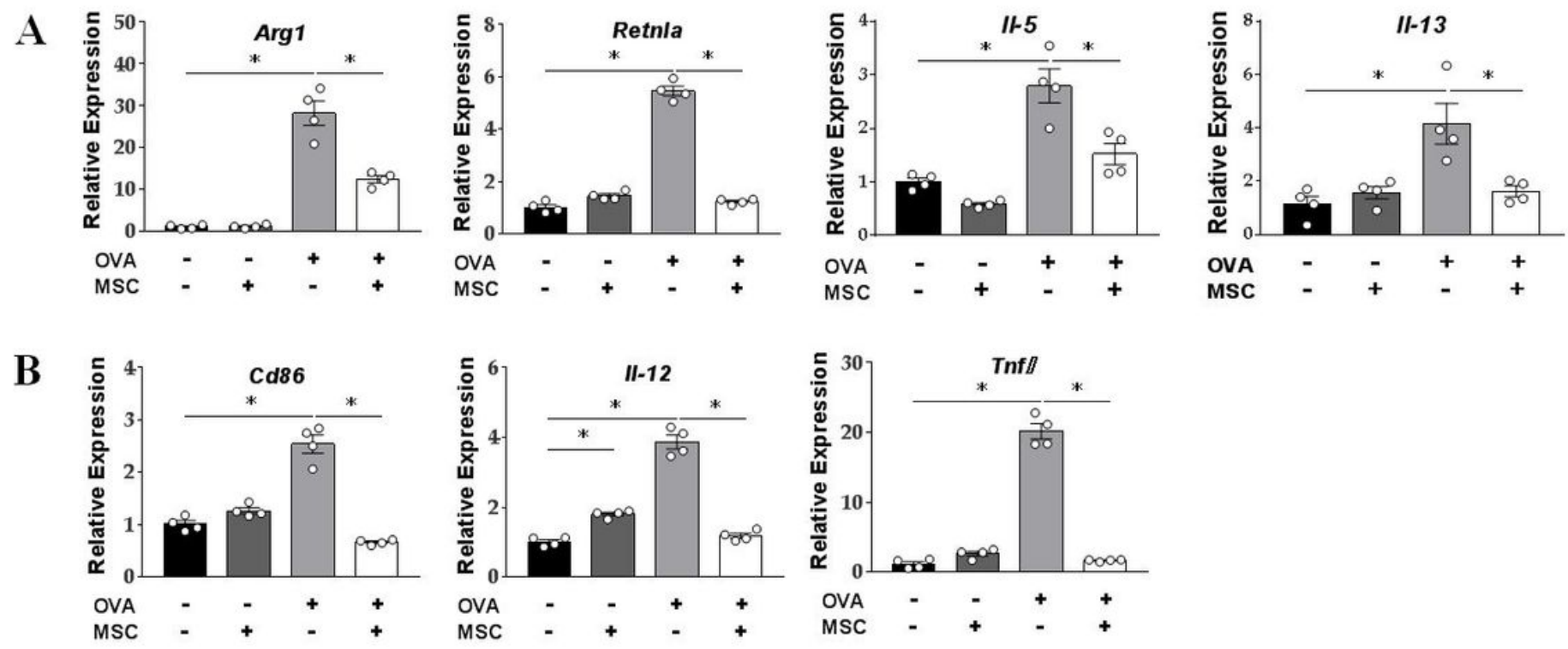

Figure 5

Effect of ucMSCs on mRNA expression of lung macrophages in a murine asthma model. (A, B) Changes in lung macrophage mRNA expression of Arg1, Retnla, IL-5, II-13(A), Cd86, II-12, and Tnfa (A),. n=4 for each group, * indicates $p<0.05$. All results are representative of at least three independent experiments. 
Fig 6.

A

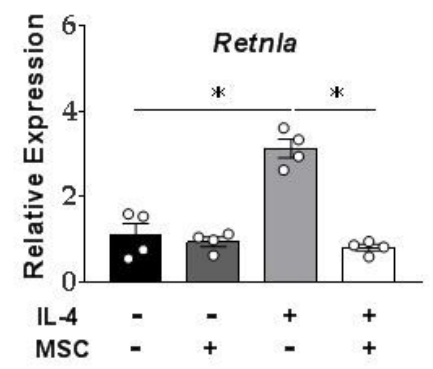

B
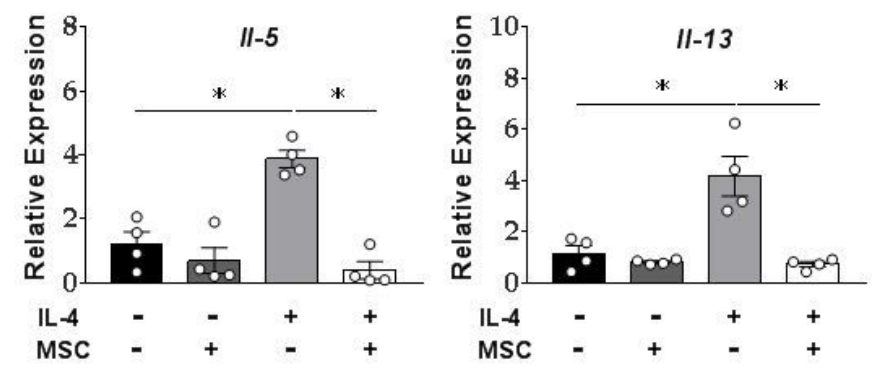

C
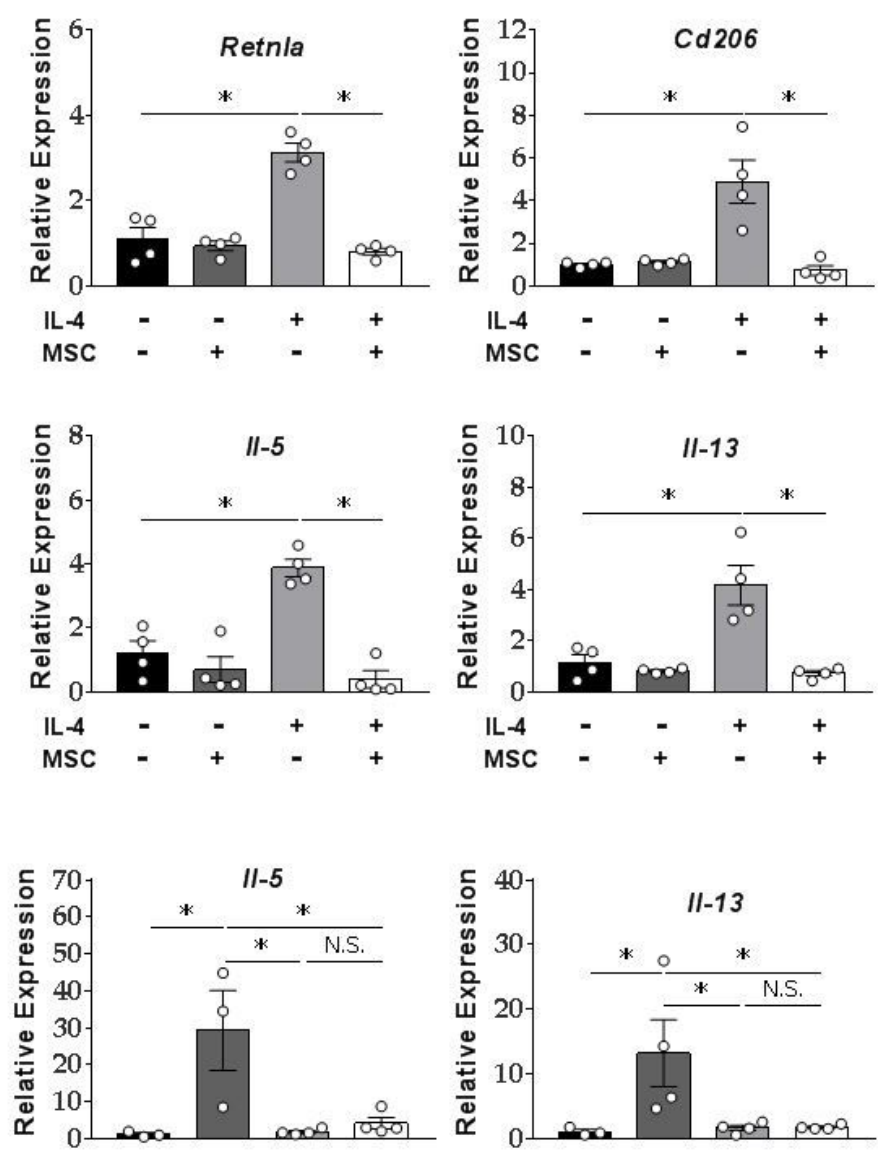
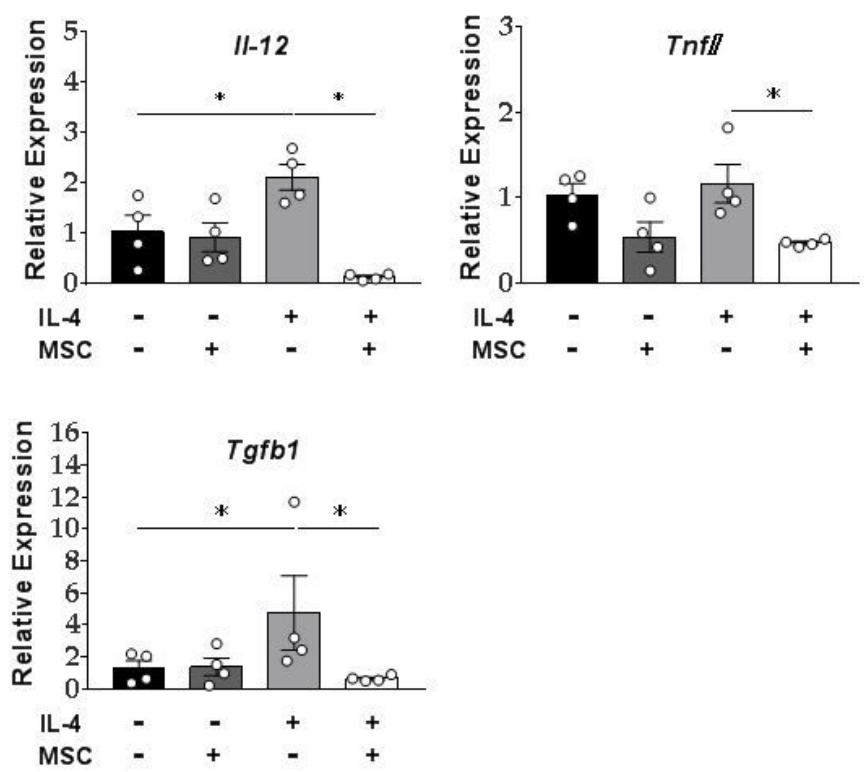

- PBS

$\square \mathrm{IL}-4$

$\square \mathrm{IL}-4+\mathrm{MSC} 1 \times 10^{4}$ (direct)

$\square \mathrm{IL}-4+$ MSC $1 \times 10^{4}$ (transwell)

\section{Figure 6}

Effect of ucMSCs on mRNA expression of ex vivo and in vitro macrophage. ( $A$ and $B$ ) Changes in ex vivo BAL fluid macrophage mRNA expression of Retnla, Cd206, II-12, Tnfa(A), II-5, II-13, and Tgfb1 (B). (C) Changes in in vitro macrophage mRNA expression of II-5 and II-13. $n=3-4$ for each group, * indicates $p<$ 0.05. All results are representative of at least three independent experiments. BAL: bronchoalveolar lavage

\section{Supplementary Files}

This is a list of supplementary files associated with this preprint. Click to download.

- SupplementryTable1.pptx

- Supplementryfigure1to7.pptx 